\title{
Are swimming coaches ready to help injured young swimmers?
}

\author{
Goran Dimitrić ${ }^{1}$, Milorad Jakšić ${ }^{1}$, Filip Sadri ${ }^{1}$, Nataša Zenić ${ }^{2}$ \\ ${ }^{1}$ Faculty of Sport and Physical Education, University of Novi Sad, Serbia; ${ }^{2}$ Faculty of Kinesiology, University of Split, \\ Croatia
}

\begin{abstract}
Study aim: This study aimed to determine the knowledge and skills of swimming coaches in providing first aid and cardiopulmonary resuscitation (CPR).

Material and methods: The sample consisted of 59 swimming coaches who responded to non-standardized questionnaire. The collected data were processed by the statistical program IBM SPSS (20.0), using the Chi-square test with cross-tabulation, with a level of statistical significance $\mathrm{p} \leq 0.05$.

Results: Obtained data showed a statistically significant difference in the knowledge of swimming coaches about first aid and CPR in relation to coaching experience $(\mathrm{p}=0.025)$; in the knowledge of providing first aid and CPR between coaches who have a certificate of first aid and CPR and those who do not $(\mathrm{p}=0.006)$ and in first aid and CPR knowledge between coaches who have renewed their first aid and CPR knowledge and those who did not $(\mathrm{p}=0.045)$.

Conclusion: Based on the findings of the present study, swimming coaches included in this research did not have enough knowledge and skills in first aid and CPR, which makes swimming programs unsafe. By obliging swimming coaches to acquire and constantly improve their knowledge and skills in first aid and CPR, the environment for all swimming programs would become safer.
\end{abstract}

Keywords: First aid and CPR - Swimming pool - Coach - Knowledge - Skills

\section{Introduction}

Swimming has a positive impact on children and adults. Children and adult swimmers are safer in and around the water environment than non-swimmers. These are perhaps the two most important reasons for the presence of a large number of children and adults attending various organized forms of swimming lessons. Nevertheless, swimming activities and swimming training are performed in the water, potentially dangerous environment where fatal outcomes can occur. The presence of lifeguards on the water, as well as a visibly marked first aid and CPR kit, during the organization of an event on the water surface, which includes all kinds of swimming training sessions are legal obligations. In case of an injury or unsafe situation, swimming coaches should be able to provide first aid and resuscitation in a timely and efficient manner. After successfully preventing drowning or some other injury that might occur in the swimming pool, until the arrival of professional medical help, properly provided first aid and resuscitation are essential and can save a life.
Watersports in swimming pools are considered healthy and are always recommended for children and adults as a form of recreation. Each sport has its specifics by which it is recognizable and, as such, is attractive to a particular subset of the general population. A large number of children are involved in swimming because it has a positive effect on their growth and development. There is a possibility of drowning during swimming training, so swimmers and coaches must be careful. Other injuries that can occur are a consequence of the structure of the movements performed by swimmers. In all activities in which specific movements are performed in a much larger number than the usual number of repetitions, injuries could occur. In swimming and water polo, the movement structures are similar, thus injuries of the spine, shoulder joint, and knee joint are common. According to some authors, the most common injury in swimmers is a shoulder injury $[1,2]$, which occurs in 40-91\% of cases [3]. Knee injuries are the second most common in swimming [4]. A survey of 36 competitive swimmers found that $86 \%$ of the sample reported at least one episode of sore knees [5]. The spinal column is also recognized as a location predisposed 
to injuries in elite swimmers. [6] Reported that 33.3\% of swimmers who swim the dolphin technique and $22.2 \%$ of swimmers who swim the breaststroke technique have experienced back pain. [7] Determined a 50\% incidence of back pain for swimmers swimming the butterfly stroke and $47 \%$ for breaststroke swimmers. Ear infections are also present as a consequence of the presence of bacteria in swimming pools. In addition to injuries caused by repeating the exact movements of the arms and legs (monostructural sport), all kind of swimmers can be injured in the pool in other ways as well. A study of injuries at swimming pools in Austria, which included 764 pool attendants, showed that $19 \%$ of injuries were lip injuries and $11.3 \%$ were dental injuries [8]. Due to a slippery floor, running around the pool or pushing by another person can suffer forearm injuries due to a fall. Injuries caused by diving in the pool are often catastrophic and have long-term consequences for both the injured and their families [9].

In countries where awareness of the importance of having the knowledge of first aid and its application exists, programs are being implemented for parents whose children are enrolled in swimming schools. In the United States, such program has contributed to improving the knowledge and skills of providing first aid to parents whose children are engaged in swimming. Compared to the level of knowledge of $47.3 \%$ at the beginning of the program, the average score immediately after the end of the program was $93.5 \%(\mathrm{t}=-12.176, \mathrm{p}<0.01)$ [10]. Physical education teachers were examined about their knowledge of first aid for dental injuries [11]. Among the examined teachers, $64 \%$ did not know what to do when a tooth fell out, while $43 \%$ knew. Although there is a legal obligation that the presence of lifeguards is mandatory at swimmers' training in Serbia, their presence is noticeable in a very small number of pools. The lifeguards are mostly young people, quite inexperienced, poorly paid, and perhaps insufficiently motivated to work in such responsible duty. As adolescents and young people, many lifeguards are unprepared to deal with the responsibility of their positions [12]. In such circumstances, it would be of great importance for swimming coaches in the Republic of Serbia to have theoretical knowledge and skills to provide first aid and CPR when necessary. The aim of this study is to determine the level of knowledge and skills of providing first aid and CPR of swimming coaches.

\section{Material and methods}

The sample consisted of 59 male coaches (aged 18-50; work experience of 1-30 years), from the Autonomous Province of Vojvodina, who voluntarily participated in the research. According to the coaching experience, there were three groups of coaches. The first group of coaches is the group with the least experience (1-10 years), the second group (11-20 years) with medium experience and the third group (21-30 years) with the most experience. The research had an empirically non-experimental character of the transversal type, in which a non-standardized questionnaire was used (Appendix). For the swimming training safety in the area of AP Vojvodina, the knowledge and skills of providing first aid and CPR of swimming coaches are of great importance. For the purposes of this research, it was necessary to create a questionnaire. The questionnaire consisted of questions about having a first aid certificate and CPR, experience in providing first aid and CPR and existence of a first aid kit and CPR at the pool where they work. The collected data were processed by the statistical program IBM SPSS (20.0), using the Chi-square test with cross-tabulation, with a level of statistical significance $\mathrm{p} \leq 0.05$.

\section{Results}

Table 1 shows the results of the analysis of whether the knowledge and skills of swimming coaches differ in relation to the years of coaching experience. Statistically significant differences $(\mathrm{p}=0.025)$ regarding the knowledge of first aid and CPR were found between coaches in relation to their experience. Coaches $(\mathrm{N}=12)$ with experience up to 10 years have knowledge of first aid and CPR, while their older colleagues with decades of experience (21 to 30 years) do not have such knowledge. In the group of coaches $(\mathrm{N}=17)$ with coaching experience of 11 to 20 years, only two of them knew how to provide first aid and CPR. No statistically significant difference $(p=0.131)$ was found between the years of coaching experience and their first aid and CPR skills. The most skilled in providing first aid were coaches with coaching experience up to 10 years, and the least skilled coaches $(\mathrm{N}=6)$ with coaching experience from 20 to 30 years.

It was also determined whether there is a difference in the ability to provide first aid and CPR between coaches who own first aid and CPR certificate and those coaches who do not (Table 2). There was a statistically significant difference $(p=0.006)$ in the knowledge of first aid and CPR between coaches who have and those who do not have this certificate. The majority of coaches (58.3\%), although they have a first aid certificate and CPR, did not give correct answers in the questionnaire.

The results of the research (Table 3) indicated that the largest number of coaches, as many as $71.2 \%$, did not renewed their knowledge of first aid and CPR, and there is a statistically significant difference $(p=0.045)$ in the knowledge of first aid and CPR between coaches who renewed their knowledge and those who did not. The 
Table 1. Contingency table of knowledge and skills of first aid and CPR in relation to the years of coaching experience of the respondents

\begin{tabular}{|c|c|c|c|c|c|c|}
\hline \multirow{2}{*}{ Variable } & & & \multicolumn{3}{|c|}{ Group } & \multirow{2}{*}{ Total } \\
\hline & & & up to 10 & $11-20$ & $21-30$ & \\
\hline \multirow{6}{*}{$\begin{array}{l}\text { First aid and CPR } \\
\text { knowledge }\end{array}$} & & Frequency & 12 & 2 & 0 & 14 \\
\hline & Know & $\%$ in group & $36.4 \%$ & $11.1 \%$ & $0 \%$ & $23.3 \%$ \\
\hline & & $\%$ total & $20.0 \%$ & $3.3 \%$ & $0 \%$ & $23.3 \%$ \\
\hline & & Frequency & 21 & 15 & 9 & 45 \\
\hline & Don't know & $\%$ in group & $63.6 \%$ & $88.9 \%$ & $100.0 \%$ & $76.7 \%$ \\
\hline & & $\%$ total & $35.0 \%$ & $26.7 \%$ & $15.0 \%$ & $76.7 \%$ \\
\hline \multirow{3}{*}{ Total } & & Frequency & & 17 & 9 & 59 \\
\hline & & $\%$ in group & $100.0 \%$ & $100.0 \%$ & $100.0 \%$ & $100.0 \%$ \\
\hline & & $\%$ total & $55.0 \%$ & $30.0 \%$ & $15.0 \%$ & $100.0 \%$ \\
\hline \multirow{6}{*}{$\begin{array}{l}\text { First aid and CPR } \\
\text { 000skills }\end{array}$} & & Frequency & 24 & 8 & 6 & 38 \\
\hline & Know & $\%$ in group & $72.7 \%$ & $44.4 \%$ & $66.7 \%$ & $63.3 \%$ \\
\hline & & $\%$ total & $40.0 \%$ & $13.3 \%$ & $10.0 \%$ & $63.3 \%$ \\
\hline & & Frequency & 9 & 9 & 3 & 21 \\
\hline & Don’t know & $\%$ in group & $27.3 \%$ & $55.6 \%$ & $33.3 \%$ & $36.7 \%$ \\
\hline & & $\%$ total & $15.0 \%$ & $16.7 \%$ & $5.0 \%$ & $36.7 \%$ \\
\hline \multirow{3}{*}{ Total } & & Frequency & 33 & 17 & 9 & 59 \\
\hline & & $\%$ in group & $100.0 \%$ & $100.0 \%$ & $100.0 \%$ & $100.0 \%$ \\
\hline & & $\%$ total & $55.0 \%$ & $30.0 \%$ & $15.0 \%$ & $100.0 \%$ \\
\hline
\end{tabular}

Knowledge: $\div 2=7.374, \mathrm{p}=0.025$; skill: $\div 2=4.063, \mathrm{p}=0.131$

Table 2. Frequencies of first aid and CPR knowledge responses between coaches who own a first-aid certificate and those who do not

\begin{tabular}{|c|c|c|c|c|c|}
\hline \multirow{2}{*}{ Variable } & & & \multicolumn{2}{|c|}{ Group } & \multirow[b]{2}{*}{ Total } \\
\hline & & & Have & Don't have & \\
\hline \multirow{6}{*}{$\begin{array}{l}\text { First aid and CPR } \\
\text { knowledge }\end{array}$} & & Frequency & 10 & 4 & 14 \\
\hline & Know & $\%$ in group & $41.7 \%$ & $11.1 \%$ & $23.7 \%$ \\
\hline & & $\%$ total & $16.7 \%$ & $6.7 \%$ & $23.7 \%$ \\
\hline & & Frequency & 14 & 31 & 45 \\
\hline & Don't know & $\%$ in group & $58.3 \%$ & $88.9 \%$ & $76.3 \%$ \\
\hline & & $\%$ total & $23.3 \%$ & $53.3 \%$ & $76.3 \%$ \\
\hline \multirow{3}{*}{ Total } & & Frequency & 24 & 35 & 59 \\
\hline & & $\%$ in group & $100.0 \%$ & $100.0 \%$ & $100.0 \%$ \\
\hline & & $\%$ total & $39.0 \%$ & $61.0 \%$ & $100.0 \%$ \\
\hline
\end{tabular}


Table 3. Frequencies of knowledge in first aid between coaches who renew first aid and CPR knowledge and those who do not

\begin{tabular}{|c|c|c|c|c|c|}
\hline \multirow{2}{*}{ Variable } & & & \multicolumn{2}{|c|}{ Group } & \multirow[b]{2}{*}{ Total } \\
\hline & & & Renew & Don't renew & \\
\hline \multirow{6}{*}{$\begin{array}{l}\text { First aid and CPR } \\
\text { knowledge }\end{array}$} & & Frequency & 7 & 7 & 14 \\
\hline & Know & $\%$ in group & $41.2 \%$ & $16.7 \%$ & $23.7 \%$ \\
\hline & & $\%$ total & $11.9 \%$ & $11.9 \%$ & $23.7 \%$ \\
\hline & & Frequency & 10 & 35 & 45 \\
\hline & Don't know & $\%$ in group & $58.8 \%$ & $83.3 \%$ & $76.3 \%$ \\
\hline & & $\%$ total & $16.9 \%$ & $59.3 \%$ & $76.3 \%$ \\
\hline \multirow{3}{*}{ Total } & & Frequency & 17 & 42 & 59 \\
\hline & & $\%$ in group & $100.0 \%$ & $100.0 \%$ & $100.0 \%$ \\
\hline & & $\%$ total & $28,8 \%$ & $71,2 \%$ & $100.0 \%$ \\
\hline
\end{tabular}

$\div 2=4.017, \mathrm{p}=0.045$.

majority of coaches $(\mathrm{N}=10)$ who renewed their knowledge of first aid and CPR, according to the answers given in the questionnaire, did not confirm it (Table 3).

By analyzing the correct answers from the survey, the skills of providing first aid and CPR to the swimming coach were assessed. As many as 34 coaches would have reacted wrongly if they encountered emergency situations, which were described in the survey. It can be said that the knowledge of swimming coaches about providing first aid and CPR is insufficient.

In addition to knowledge and skills, successful first aid requires a positive attitude of the coach towards this skill and its continuous improvement. It is expected that the coaches are ready to continuously improve their first aid skills. Positive attitude (desire and will) towards the continuous improvement of knowledge and skills of first aid and CPR, expressed by 57 swimming coaches.

\section{Discussion}

A survey was conducted on a sample of 59 swimming coaches, who teach children aged 6-18 to swim or conduct a training process on them. The safety of young swimmers in the pools where the tested coaches are employed is low. Most of the coaches $(\mathrm{N}=46)$ reported that there were no first aid kits and CPRs at the pools where they were employed, as well as lifeguards during the training. Only 39 swimming coaches were certified to provide first aid and CPR. Each respondent confirmed that the safety of swimmers is very important. Out of a total of 59 coaches, 14 of them would know and 38 would be able to provide first aid and CPR. This result is very worrying. Unfortunately, there are many worrying examples. A questionnaire was conducted on football officials responsible for dealing with injuries, who note that 34 out of 86 examinees had a first aid certificate [13]. In Northern Ireland and the Republic of Ireland, a survey was conducted on physical education teachers and coaches from 450 schools. Based on the analyzed answers, it was determined that $37 \%$ of physical education teachers did not renew their knowledge of first aid [14]. In England, the qualifications and knowledge of first aid among coaches and officials in five non-elite youth sports were determined. It was found that $80 \%$ of respondents have an updated first aid certificate, but around $50 \%$ of total participants did not know how to react properly in "collapsed player" and "choking player" scenario [15]. Survey conducted in Turkey indicates insufficient level of knowledge about first aid among surveyed preschool teachers [16], primary school teachers [17], physical education teachers [18], and university sports team coaches [19]. Coaches are important figure in transfering their knowledge and skills to younger and less experienced athletes.

The most inexperienced trainers had the most knowledge in providing first aid and CPR. It could be assumed that younger coaches were trained for the profession of coach, so they are more aware of the importance of the aspect of children's safety in training. More experienced coaches worked as coaches as additional work, without any training. They did not have the opportunity to acquire knowledge and skills in the field of this research. Knowing that the safety of swimmers is of critical importance, American Red Cross has a program named "Safety training for Swim Coaches" and has made it mandatory for every swimming coach across US. This program had the aim to inform swimmers about possible life-threatening situations in the water and around water and techniques and skills to prevent and deal with them [20]. Most of the surveyed coaches work with children, so they would have 
to master this knowledge and skills from a professional and especially ethical point of view. Possession of a certificate implies a level of training in an area. Coaches and administrators have an ethical responsibility to prepare for emergency care situations [21]. The obtained results of this research deny this fact because more coaches without a first aid certificate and CPR had more knowledge than their colleagues with the mentioned certificate. This result can be a consequence of not using the mentioned knowledge and learned skills or poorly performed first aid and CPR certification renewal. In addition to knowledge and skills, successful first aid and CPR requires selfconfidence, courage, and a positive attitude of the coach. A positive attitude could contribute to encouraging and raising the necessary self-confidence to master at least the basic knowledge and skills of first aid and CPR. Most of the swimming coaches included in this research expressed a positive attitude. This indicates that coaches are aware of the risks that can occur in the pool and the importance of having the knowledge and skills in providing first aid and CPR to those who need it. Safety conditions for swimming training on the territory of AP Vojvodina are at a low level, so it would be best to oblige all coaches by law to attend a first aid course and CPR. Swimming coaches do not often come to the situation that they have to save someone's life or provide first aid and CPR, so it would be good to periodically update their knowledge or raise it to a higher level. Even short lessons in CPR could improve self-confidence of medical and non-medical personnel [22]. The results of this research indicate that most coaches do not renew their knowledge of first aid and CPR. Training on providing CPR for volunteers has been organized in the UK. Six months after the training, of the total sample, only $7 \%$ managed to perform CPR safely [23]. Failure to renew previously learned knowledge and skills reduces the quality of their performance and self-confidence.

The limitations of this research are a small number of coaches who agreed to participate in the research and testing of first aid and CPR skills. A limitation of this study was the use of a non-standardized questionnaire, which was constructed for our study, so the results obtained cannot be compared with similar research. A wide range of coaches age and work experience are llimitation also.

\section{Conslusions}

The swimming coaches included in this research did not show enough knowledge and skills in providing first aid and CPR, which makes most of the swimming programs unsafe. Lifeguards are present at a small number of swimming pools in AP Vojvodina (Serbia) during swimming training, and life-threatening situations can occur. Every coach should know how and be able to provide first aid and CPR. It is encouraging that less experienced coaches have better first aid and CPR skills compared to experienced coaches, despite the fact that some of the older coaches have a first aid and CPR certificate. Young swimmers could be safer if their coaches knew how to provide first aid and CPR. By obliging swimming coaches to attend first aid and CPR courses, the safety in swimming programs would be improved. The knowledge and capability of providing first aid and CPR skills could be a condition for obtaining a national license to work on the pool.

Conflict of interest: Authors state no conflict of interest.

\section{References}

1. Abernethy L., Macauley D., McNally O., McCann S. (2003) Immediate care of school sport injury. Inj. Prev., 9(3): 270-273. DOI: 10.1136/ip.9.3.270.

2. Bak K. (2010) The practical management of swimmer's painful shoulder: etiology, diagnosis, and treatment. Clin. J Sport Med., 20(5): 386-390. DOI: 10.1097/ JSM.0b013e3181f205fa.

3. Barss P., Djerrari H., Leduc B.E., Lepage Y., Dionne C.E. (2008) Risk factors and prevention for spinal cord injury from diving in swimming pools and natural sites in Quebec, Canada: A 44-year study. Accident Anal. Prev., 40(2): 787-797 DOI: 10.1016/j.aap.2007.09.017.

4. Başer M., Coban S., Taşci S., Sungur G., Bayat M. (2007) Evaluating first-aid knowledge and attitudes of a sample of Turkish primary school teachers. J. Emerg. Nurs., 33(5); 428-432. DOI: 10.1016/j.jen.2006.11.003.

5. Brushoj C., Bak K., Johannsen H.V., Fauno P. (2007) Swimmers' painful shoulder arthroscopic findings and return rate to sports. Scand. J. Med. Sci. Sport, 17(4): 373-377. DOI: 10.1111/j.1600-0838. 2006.00571.x.

6. Capaci K., Ozcaldiran B., Durmaz B. (2002) Musculoskeletal pain in elite competitibe male swimmers. Pain Clinic, 14: 229-234. DOI: 10.1163/156856902320761432.

7. Cunningham A. (2002) An audit of first aid qualifications and knowledge among team officials in two English youth football leagues: a preliminary study. Br. J. Sport Med., 36: 295-300. DOI: 10.1136/bjsm.36.4.295.

8. Dincer, C., Atakurt, Y., Simsek, I. (2000) A study on the lever of the first aid knowledge educators working in preschools. Journal of Ankara University Faculty of Medicine, 53(1): 31-38. (In Turkish).

9. Drori A., Mann G. Constantini N. (1996) Low back pain in swimmers: is the prevalence increasing? In: The 12th International Jerusalem Symposium on Sports Injuries; Tel Aviv, Israel.

10. Kobras M., Langewand S., Murr C., Neu C., Schmid J. (2016) Short lessons in basic life support improve self- 
assurance in performing cardiopulmonary resuscitation. World Journal of Emergency Medicine, 7(4): 255-262. DOI: 10.5847/wjem.j.1920-8642.2016.04.003.

11. Korkusuz F., Tüzün M., Saraç L. (2005) First aid knowledge of physical education teachers. The ICHPER-SD Annivarsary World Congress, Istanbul, 2005, November, 9-13.

12. Lechner K., Connert T., Kühl S., Filippi A. (2017) Lip and tooth injuries at public swimming pools in Austria. Dent. Traumatol., 33(3): 214-220. DOI: 10.1111/edt.12331.

13. McCarrison R., Ren D., Woomer G.R. Cassidy B. (2017) Evaluation of a Self-Instructional CPR Program for Parents With Children Enrolled in Community Swim Lessons. J. Pediatr. Health Car., 31(3): 314-319. DOI: 10.1016/j.pedhc.

14. Morgan C.L., Donnelly P.D., Lester C.A., Assar D.H. (1996) Effectiveness of the BBC's 999 training roadshows on cardiopulmonary resuscitation: video performance of cohort of unforewarned participants at home six months afterwards. BMJ (Clinical research ed.), 313(7062): 912-916. DOI: 10.1136/bmj.313.7062.912.

15. Newman L.J., Crawford P.J. (1991) Dental injuries: “first aid" knowledge of Southampton teachers of physical education. Dent. Traumatol., 7(6): 255-258. DOI:10.1111/ j.1600-9657.1991.tb00213.x.

16. Robertello K., Barnes J., Stoll S. (2009) Ethical responsibilities of coaches in emergency care situations: are you prepared? Western Society Review, 36.

17. Rodeo S.A. (2004) Swimming. In: Krishnan S.G., Hawkins R.J., Warren R.F. (eds.), The shoulder and the overhead athlete. Philadelphia, PA: Lippincott: Williams \& WIlkins, p. 350.
18. Rupp S., Berninger K., Hopf T. (1995) Shoulder problems in high level swimmers: impingement, anterior instability, muscular imbalance? Int. J. Sports Med., 16(8): 557-562. DOI: 10.1055/s-2007-973054.

19. Schwebel D.C., Jones H.N., Holder E. Marciani F. (2010) Lifeguards: A Forgotten Aspect of Drowning Prevention. J. Inj. Violence Res., 2(1): 1-3. DOI: 10.5249/jivr.v2i1.32.

20. Sein M.L., Walton J., Linklater J., Appleyard R., Kirkbride B., Kuah D. Murrell G.A. (2010) Shoulder pain in elite swimmers: primarily due to swim-volume-induced supraspinatus tendinopathy. Br. J. Sport Med., 44(2): 105-113. DOI: 10.1136/bjsm.2008.047282.

21. The American Red Cross. (2008) "Safety Training for Swim Coaches". Retrived from https://www.redcross. org/content/dam/redcross/atg/PDFs/Take_a_Class/ STSC_Supplement_071913.pdf.

22. Tüzün M., Saraç L. (2005) A descriptive study on the knowledge of first aid among university sports team coaches. Universiade 2005 İzmir FISU Conference. 12-14 August, Ege University Ataturk Cultural Center, İzmir, Turkey.

23. Whitaker J., Cunningham A., Selfe J. (2007) A study to determine the extent of first aid qualifications and knowledge among team officials in non-elite youth sport in England. Int. J. Emerg. Med., 3(2).

\section{Received 21.09.2021 \\ Accepted 06.11.2021}

(C) University of Physical Education, Warsaw, Poland 